\title{
Metal sorption on soils as affected by the dissolved organic matter in sewage sludge and the relative calculation of sewage sludge application
}

\author{
Xiaoli Liu ${ }^{\mathrm{a}, \mathrm{b}}$, Shuzhen Zhang ${ }^{\mathrm{a}, *}$, Wenyong $\mathrm{Wu}^{\mathrm{c}}$, Honglu Liu ${ }^{\mathrm{c}}$ \\ a State Key Laboratory of Environmental Chemistry and Ecotoxicology, Research Center for Eco-Environmental Sciences, \\ Chinese Academy of Sciences, P.O. Box 2871, Beijing 100085, China \\ ${ }^{\mathrm{b}}$ Environment and Engineering Division, China Electronics Engineering Design Institute, Box 307, Beijing 100840, China \\ ${ }^{\mathrm{c}}$ Beijing Hydraulic Research Institute, Beijing 100044, China \\ Received 1 November 2006; received in revised form 2 April 2007; accepted 2 April 2007 \\ Available online 6 April 2007
}

\begin{abstract}
To evaluate the influences of sewage sludge-derived organic matters on metal sorption and on the resultant sludge loading estimates, a batch experiment was conducted to compare the sorption of $\mathrm{Ni}, \mathrm{Cu}$ and $\mathrm{Pb}$ in sewage sludge filtrates (1:20 sewage sludge to water) on eight soils and the adsorption of metals in a reference solution which had the same matrix as the sewage sludge filtrate except dissolved organic material (henceforth referred to as reference solution). Metal sorption could be well fitted by linear isotherm and the dissolved organic matter in sludge significantly depressed the sorption $(p<0.01)$. The main factor controlling sorption of Ni on different soils was dominated by soil cation exchange capacity (CEC) and sorption of $\mathrm{Cu}$ and $\mathrm{Pb}$ was by soil organic matter ( $\mathrm{SOM}$ ). The parameters obtained from the sorption isotherm equations were then used to estimate sludge loadings into the soils. When the sorption parameters derived from the reference solution were used for calculation, that is the effect of dissolved organic matter was not considered, the calculated safe application rates are approximately 47.8, 51.4, 34.2, 31.3, 21.7, 46.3, 187.1 and 27.6t-sludge/ha for the Beijing, Jiangxi, Xiamen, Jilin, Guangdong, Wuhan, Gansu and Xinjiang soils, respectively. However, when the sorption parameters derived from the dissolved organo-metallic complexes are used for calculation, the corresponding application rates are reduced to approximately 6.0, 3.4, 1.9, 10.0, 6.3, 3.6, 7.3 and $3.5 \mathrm{t}$-sludge/ha, respectively. By this study we can get a conclusion that the effect of sewage sludge derived dissolved organic matter on heavy metal sorption and soil properties should be considered in the course of regulating the safe application rates of sewage sludge to soil.
\end{abstract}

(C) 2007 Elsevier B.V. All rights reserved.

Keywords: Sewage sludge; Dissolved organic matter (DOM); Metal; Sorption; Sludge application rate

\section{Introduction}

Application of sewage sludge to agricultural soil is a common practice because of low costs and recycling of nutrients achieved [1]. However, this practice can pose a threat to environment and the major concern arises from the fact that sewage sludge, especially those from the heavily urbanized and industrialized areas, contains a relatively high concentration of heavy metals. Thus application of sewage sludge to agricultural soil may result in elevated concentrations of toxic metals, which may then threaten ground water quality and lead to food chain contamination $[2,3]$.

\footnotetext{
* Corresponding author. Tel.: +86 1062849683 ; fax: +86 1062923563 .

E-mail address: szzhang@ rcees.ac.cn (S. Zhang).
}

The fate of heavy metals in sewage sludge is mainly related to their mobility in soil. A traditionally held view on the mobility of heavy metals in sewage sludge-amended soils is that the metals' migration is insignificant and the metals tend to remain in the site of input, i.e. in the topsoil [4-7]. However, in several field-base experiments the apparent migration of heavy metals to the deep was observed [8,9]. Furthermore, in column leaching [10] and batch [11] experiments, it has been shown that heavy metal ions may leach more easily in the presence of sewage sludge than in its absence. They ascribed such elevated mobility to the high contents of dissolved organic matter (DOM) in sewage sludge. Due to its net negative charge at typical soil $\mathrm{pH}$, DOM generally moves very easily through soil system [12]. On the other hand, DOM has the ability to form stable and soluble complexes with heavy metals, which can be maintained in soil solution and thereby transport in soil. Therefore, in 
order to elucidate the fate of heavy metals in sewage sludge in the context of land application, it is necessary to understand the influences of DOM derived from sewage sludge on heavy metal adsorption. However, among the relevant researches very limited investigated sorption of real sludge-borne heavy metals.

In addition, metal sorption on soils is strongly related to soil properties. Researches have shown that metal sorption by soils increased with increasing the $\mathrm{pH}$ [13], organic matter [14,15], cation exchange capacity [16], and the contents of iron and manganese oxides. However, there is a lack of information concerning the adsorption of sludge-borne heavy metals on different soils [17]. To gain further insight into the behaviors of heavy metals in sewage sludge after application to soil, we need to investigate the influence of soil properties on the sorption of sludge-borne heavy metals and, as to our knowledge, there is no such information in literatures up to now.

Soil has a high binding capacity for heavy metals, which is dependent on metal species and physiochemical properties of the soil. In case DOM in sewage sludge decreases metal sorption, and thereby increases their mobility in soil, there might be a greater potential for adverse impacts on the surrounding environment. The most direct and obvious impact is the threat to ground water quality. Therefore, when we calculate the sludge application rate to agriculture land, it is necessary to consider the effects of DOM derived from sewage sludge on heavy metal sorption and also of the soil physicochemical properties.

The purpose of the present study, therefore, includes three parts (1) to evaluate the effect of the dissolved organic matter derived from sewage sludge on heavy metal sorption on soils by comparing the sorption of heavy metals in sewage sludge filtrate and the reference solutions which contained the same concentration of trace heavy metals, major cation and anion composition as the sewage sludge filtrates except DOM; (2) to establish the relationship between the sorption of sludge-borne heavy metals and soil physiochemical properties; and (3) to estimate the sludge application rates to different soils by considering the influence of the DOM derived from sludge on heavy metal sorption.

\section{Materials and methods}

\subsection{Sewage sludge}

Sewage sludge sample was obtained from Gaobeidian wastewater treatment works in Beijing, China. The sample was air-dried, homogenized and ground to pass through $1 \mathrm{~mm}$ nylon fiber sieve and was then stored in dark at $4{ }^{\circ} \mathrm{C}$ for subsequent analysis and usage.

Sewage sludge was extracted with deionized water using a solid to water ratio of 1:20 (w/v). The mixture was shaken on an end-over-end shaker for $24 \mathrm{~h}$ at $22 \pm 2{ }^{\circ} \mathrm{C}$. After centrifuged at $8000 \mathrm{rpm}$ for $10 \mathrm{~min}$ the suspension was filtered through a 0.45 $\mu \mathrm{m}$ cellulose nitrate membrane. Concentrations of $\mathrm{Cu}, \mathrm{Ni}$ and $\mathrm{Pb}$ were determined by inductively coupled plasma mass spectrometry (ICP-MS, PQ3, Fisons instruments, UK); the contents
Table 1

Characteristics of the experimental sewage sludge (water-extractable component: 1:20 solid to water)

\begin{tabular}{ll}
\hline $\mathrm{Ca}(\mathrm{mg} / \mathrm{L})$ & 200.09 \\
$\mathrm{Mg}(\mathrm{mg} / \mathrm{L})$ & 41.43 \\
$\mathrm{Al}(\mu \mathrm{g} / \mathrm{L})$ & 45.23 \\
$\mathrm{Na}(\mathrm{mg} / \mathrm{L})$ & 5.12 \\
$\mathrm{~K}(\mathrm{mg} / \mathrm{L})$ & 4.92 \\
$\mathrm{Cu}(\mu \mathrm{g} / \mathrm{L})$ & 35.80 \\
$\mathrm{Zn}(\mu \mathrm{g} / \mathrm{L})$ & 65.88 \\
$\mathrm{Ni}(\mu \mathrm{g} / \mathrm{L})$ & 361.06 \\
$\mathrm{Mn}(\mathrm{mg} / \mathrm{L})$ & 1.44 \\
$\mathrm{Fe}(\mathrm{mg} / \mathrm{L})$ & 24.87 \\
$\mathrm{~Pb}(\mu \mathrm{g} / \mathrm{L})$ & 2.31 \\
$\mathrm{Cd}(\mu \mathrm{g} / \mathrm{L})$ & 5.95 \\
$\mathrm{pH}^{-}$ & 7.19 \\
$\mathrm{NO}_{3}{ }^{-}(\mathrm{mg} / \mathrm{L})$ & 356.90 \\
$\mathrm{Cl}^{-}(\mathrm{mg} / \mathrm{L})$ & 18.99 \\
$\mathrm{PO}_{4}{ }^{3-}(\mathrm{mg} / \mathrm{L})$ & 85.48 \\
$\mathrm{~F}^{-}(\mathrm{mg} / \mathrm{L})$ & 41.49 \\
$\mathrm{SO}_{4}{ }^{2-}$ & Not detected \\
\hline
\end{tabular}

of $\mathrm{NO}_{3}{ }^{-}, \mathrm{F}^{-}, \mathrm{SO}_{4}{ }^{2-}, \mathrm{PO}_{4}{ }^{3-}$ and $\mathrm{Cl}^{-}$were analyzed by ion chromatography (Dionex, Sunnyvale, CA, USA). The filtrate was analyzed for $\mathrm{pH}$ (Orion 902A Ion-analyzer) and dissolved organic carbon (DOC) by a total organic carbon autoanalyzer (TOC-5000A; Shimadzu, Kyoto, Japan). Total carbon was determined using elemental analysis (EA, Vario EI, Elementar Co., Germany). DOC operational fractionation was carried out by the method developed by Leenheer [18]. Cation exchange capacity (CEC) was determined by the method of Rhoades [19]. Total concentrations of $\mathrm{Cu}, \mathrm{Ni}$ and $\mathrm{Pb}$ in sludge were determined by ICP-MS after aqua regia digestion. Dissolved $\mathrm{Cu}, \mathrm{Ni}$ and $\mathrm{Pb}$ were also determined by ICP-MS. The characteristics of the sludge filtrate were listed in Table 1.

\subsection{Soils}

Eight topsoil samples $(0-20 \mathrm{~cm})$ were collected from different provinces in China, which represent the typical Chinese soils with different physical and chemical properties. $\mathrm{S}_{1}, \mathrm{~S}_{2}, \mathrm{~S}_{3}, \mathrm{~S}_{4}$, $\mathrm{S}_{5}, \mathrm{~S}_{6}, \mathrm{~S}_{7}$ and $\mathrm{S}_{8}$ represent the eight soils from Beijing, Jiangxi, Xiamen, Jilin, Guangdong, Wuhan, Gansu and Xinjiang, respectively. Samples were dried under aerated condition and ground to pass through $1 \mathrm{~mm}$ nylon fiber sieve, and stored for subsequent analysis and usage.

Soil $\mathrm{pH}$ was measured at 1:10 (w:v) soil:water solution ratio. Organic matter content was determined according to the method of Nelson [20]. Dissolved organic carbon was determined by the total organic carbon analyzer after shaking $1 \mathrm{~g}$ of soil in $10 \mathrm{~mL}$ deionized water for $24 \mathrm{~h}$, centrifuging $(4000 \mathrm{rpm})$ and filtering through a $0.45-\mu \mathrm{m}$ cellulose nitrate membrane. Soil CEC, total carbon, $\mathrm{Cu}, \mathrm{Ni}, \mathrm{Pb}$, dissolved $\mathrm{Cu}, \mathrm{Ni}$ and $\mathrm{Pb}$ in the soils were determined by the same method as for the sewage sludge. Soil texture was obtained by Laser Particle Analyzer after destroying the organic matter by $30 \% \mathrm{H}_{2} \mathrm{O}_{2}$ and dispersing the aggregates in the soil by sodium hexametaphosphate [21]. All measurements were conducted in triplicates. 


\subsection{Sorption isotherms}

\subsubsection{Preparation of filtrate and reference solutions}

The filtrate was obtained by extracting from the sludge with deionized water using a solid to water ratio of 1:20 (w:v). This mixture was shaken on an end-over-end shaker for $24 \mathrm{~h}$ at $22 \pm 2{ }^{\circ} \mathrm{C}$. After centrifuged at $8000 \mathrm{rpm}$ for $10 \mathrm{~min}$, the supernatant was filtered through a $0.45-\mu \mathrm{m}$ cellulose nitrate membrane, evaporated in a rotary evaporator at $50 \pm 2{ }^{\circ} \mathrm{C}$ to $20 \%$ of its initial volume, and five concentrations in the range of $0-179 \mu \mathrm{g} / \mathrm{L}$ for $\mathrm{Cu}, 0-1805 \mu \mathrm{g} / \mathrm{L}$ for $\mathrm{Ni}$ and $0-16 \mu \mathrm{g} / \mathrm{L}$ for $\mathrm{Pb}$ prepared by dilution.

In order to exam the influence of the sludge derived DOM in metal adsorption, a "reference solution" was prepared by dissolving the constituents containing the following cations and anions $\mathrm{Cu}, \mathrm{Ni}, \mathrm{Pb}, \mathrm{Cd}, \mathrm{Zn}, \mathrm{Ca}, \mathrm{Mg}, \mathrm{K}, \mathrm{Na}, \mathrm{Fe}, \mathrm{Mn}, \mathrm{Al}, \mathrm{NO}_{3}{ }^{-}$, $\mathrm{F}^{-}, \mathrm{PO}_{4}{ }^{3-}, \mathrm{Cl}^{-}$and the finial concentrations of them were as same as in the sludge filtrate. Later this solution was adjusted to the same $\mathrm{pH}$ and ionic strength as the filtrate. Therefore, the reference solution contained the same composition as the sewage sludge filtrates but no DOM in it.

\subsubsection{Sorption experiment}

Sorption isotherms were obtained by a batch technique whereby $1 \mathrm{~g}$ soil was shaken with $10 \mathrm{~mL}$ equilibrating solution for $24 \mathrm{~h}$ and centrifuged at $8000 \mathrm{rpm}$ for $10 \mathrm{~min}$. The supernatant was filtered through a $0.45-\mu \mathrm{m}$ cellulose nitrate membrane and then the concentrations of $\mathrm{Cu}, \mathrm{Ni}$ and $\mathrm{Pb}$ in the filtrates were determined. The equilibrating solution represents a concentration of $\mathrm{Cu}, \mathrm{Ni}$ and $\mathrm{Pb}(0-2 \mathrm{mg} / \mathrm{L})$ in the sewage sludge filtrate or reference solution.

\subsubsection{Adsorption fitting by equations}

Relationships between the amount of $\mathrm{Cu}, \mathrm{Ni}$ or $\mathrm{Pb}$ sorbed on the soils $\left(C_{\mathrm{s}}, \mu \mathrm{g} / \mathrm{kg}\right)$ and the equilibrium concentrations of heavy metals $\left(C_{\mathrm{a}}, \mu \mathrm{g} / \mathrm{L}\right)$ were fitted by linear isotherm. In the equation of $C_{\mathrm{s}}=K C_{\mathrm{a}}, K$ is distribution coefficient, representing the relative sorption affinity. The $K$ values were then used to assess the effects of the DOM in sludge on metal sorption on soil and the sludge loading rates to soil.

\subsection{Calculation of sludge application rate}

The sorption isotherm parameters obtained from the sorption equations were used for the calculation. First, the equilibrium concentration $\left(C_{\mathrm{a}}\right)$ in the sorption equation $C_{\mathrm{s}}=K C_{\mathrm{a}}$ was substituted by the allowable concentrations, which were adopted based on the criteria specified in the WHO Water-Drinking Quality Guidelines [22] and are $0.02 \mathrm{mg} / \mathrm{L}$ for $\mathrm{Ni}, 2 \mathrm{mg} / \mathrm{L}$ for $\mathrm{Cu}$ and $0.01 \mathrm{mg} / \mathrm{L}$ for $\mathrm{Pb}$, respectively. The amount of $\mathrm{Ni}, \mathrm{Cu}$ and $\mathrm{Pb}$ sorbed by soils was then calculated. The sorbed amount of $\mathrm{Ni}$, $\mathrm{Cu}$ and $\mathrm{Pb}$, which was considered as the allowable metal loading, was expressed on a $\mathrm{kg} / \mathrm{ha}$ basis using soil bulk density and a particular depth of soil (i.e. the A-horizon, $0-20 \mathrm{~cm}$, of the study soil). Then the sludge application rate was obtained by converting the sorbed amount of heavy metals (choosing the lowest one among $\mathrm{Ni}, \mathrm{Cu}$ and $\mathrm{Pb}$ ) to the application amount of sludge according to the heavy metal contents in sewage sludge, that is, the sorbed amount of heavy metal being divided by its proportion in the sewage sludge.

\subsection{Statistical analysis}

Statistical analysis was performed by using Microsoft-Excel, Statistical Product and Service Solutions (SPSS) 12.0, Origin 7.0, and the geochemical speciation model MINTEQAII [23]. The data represent means calculated from three replicates. A least significant difference test (LSD-test) was employed for comparison of changes at $p<0.05$.

Forward stepwise multivariate regression was used to derive best-fit models of metal adsorption by different soils and soil properties. The variance inflation factor (VIF), the condition indices and the regression coefficient variance-decomposition matrix were also considered to diagnose the colinearity between independent variables. Colinearity becomes an issue when values of VIF exceed 2.0.

\section{Results}

\subsection{Sludge, sludge filtrate and soils characteristics}

The $\mathrm{pH}$ of the sewage sludge was 7.19. The total concentrations of $\mathrm{Cu}, \mathrm{Ni}$ and $\mathrm{Pb}$ were 189.86, 27.24 and $8.90 \mathrm{mg} / \mathrm{kg}$, respectively, which were lower than the average metal contents in the sewage sludge in China [24]. The sludge sample contained $53.4 \%$ organic matter, $24.9 \mathrm{~g} / \mathrm{kg}$ DOC and $1.3 \mathrm{cmol} / \mathrm{kg}$ CEC. Speciation of $\mathrm{Ni}, \mathrm{Cu}$ and $\mathrm{Pb}$ in the sludge filtrate obtained by the model MINTEQAII [23] showed that they were present mainly as dissolved organic metallic complexes with $98.93 \%$ for $\mathrm{Ni}, 99.96 \%$ for $\mathrm{Cu}$, and $99.98 \%$ for $\mathrm{Pb}$, respectively.

The physical and chemical properties of the soils used in this study varied widely (Table 2). The soil $\mathrm{pH}$ ranged from 5.01 to 7.40 , the CEC ranged from 5.1 to $41.2 \mathrm{cmol} / \mathrm{kg}$, the soil OM contents varied from 1.55 to $4.41 \%$ and the DOC was from 274 to $740 \mathrm{mg} / \mathrm{kg}$. All these soils can be considered as uncontaminated soils [25]. According to the particle size distribution, the Xinjiang soil was sandy-loam; the Gansu and Wuhan soils were belong to silt-loam; the Beijing soil was loam; the Jilin and Xiamen soils were clay-loam; the Jiangxi and Guangdong soils were clay. Soil classification was given in Table 2.

\subsection{Sorption isotherms}

Figs. 1-3 represent the sorption data for $\mathrm{Cu}, \mathrm{Ni}$ and $\mathrm{Pb}$ on the soils. We can apparently see much lower sorptions of $\mathrm{Cu}$, $\mathrm{Ni}$ and $\mathrm{Pb}$ in the filtrates than the corresponding values for the reference solutions on all the soils. By comparing the fitness parameters obtained by linear, Langmiur and Freundlich equations, we found the linear equation was effective to provide a good fitness for the metals in both the filtrate and the reference. Therefore, the relationship between the amount of metals sorbed by the soils and the equilibrium concentrations in solution was fitted by linear equation $C_{\mathrm{s}}=K C_{\mathrm{a}}$. Satisfied fitting results obtained by linear equation could be ascribed to the low metal 
Table 2

Characteristics of the experimental soils (water-extractable component: 1:10 soil to water)

\begin{tabular}{|c|c|c|c|c|c|c|c|c|}
\hline \multirow[t]{2}{*}{ Property } & \multicolumn{8}{|l|}{ Soil } \\
\hline & $\mathrm{S}_{1}$ & $\mathrm{~S}_{2}$ & $\mathrm{~S}_{3}$ & $\mathrm{~S}_{4}$ & $\mathrm{~S}_{5}$ & $\mathrm{~S}_{6}$ & $\mathrm{~S}_{7}$ & $\mathrm{~S}_{8}$ \\
\hline Classification & Alfisols & Ultisol & Ultisol & Alfisols & Oxisol & Alfisols & Aridisols & Aridisols \\
\hline Dissolved $\mathrm{Cu}(\mu \mathrm{g} / \mathrm{kg})$ & 246.3 & 23.8 & 87.1 & 74.1 & 118.1 & 66.2 & 52.4 & 193.8 \\
\hline Dissolved Ni $(\mu \mathrm{g} / \mathrm{kg})$ & 267.6 & 245.5 & 253.6 & 245.4 & 423.1 & 1212.5 & 807.7 & 813.1 \\
\hline Dissolved $\mathrm{Pb}(\mu \mathrm{g} / \mathrm{kg})$ & 34.8 & 2.0 & 32.5 & 8.2 & 20.2 & 36.1 & 16.3 & 47.7 \\
\hline $\mathrm{pH}$ & 7.04 & 5.01 & 6.25 & 5.87 & 5.12 & 6.70 & 6.60 & 7.40 \\
\hline DOC (mg/kg) & 369.3 & 309.9 & 290.4 & 368.7 & 319.2 & 274.0 & 370.0 & 740.0 \\
\hline $\mathrm{CEC}(\mathrm{cmol} / \mathrm{kg})$ & 15.7 & 14.2 & 5.1 & 14.0 & 14.1 & 22.8 & 41.2 & 38.4 \\
\hline $\mathrm{OM}(\%)$ & 2.33 & 1.53 & 1.81 & 4.41 & 1.56 & 1.59 & 1.66 & 1.55 \\
\hline \multicolumn{9}{|l|}{ Texture } \\
\hline Clay (\%) & 23.2 & 45.6 & 29.6 & 38.6 & 26.5 & 38.1 & 18.7 & 10.8 \\
\hline Silt (\%) & 44.7 & 23.5 & 33.7 & 28.1 & 51.3 & 28.6 & 55.7 & 34.1 \\
\hline Sand $(\%)$ & 32.1 & 30.9 & 36.7 & 33.4 & 22.2 & 33.4 & 25.6 & 55.2 \\
\hline
\end{tabular}

concentrations in filtrate and reference solution. The filtrate $\mathrm{Cu}$, $\mathrm{Ni}$ and $\mathrm{Pb}$ concentrations were 35.8-179.0, 361.06-1805.3 and $2.31-11.55 \mu \mathrm{g} / \mathrm{L}$, respectively, and the metal concentrations in the reference solution were in the similar ranges. The equation parameters are given in Table 3. The ratio of the constant values $K_{1}$ for the reference solution to $K_{2}$ for the filtrate ranged from 2.5 to $8.0,2.5$ to 10.3 and 3.4 to 25.6 for $\mathrm{Ni}, \mathrm{Cu}$ and $\mathrm{Pb}$, respectively. It suggests that DOM significantly decreased $\mathrm{Ni}$, $\mathrm{Cu}$ and $\mathrm{Pb}$ sorption affinity on all the soils $(p<0.01)$. A comparison among the elements showed that the average ratio varied in

Table 3

Parameters of the linear equations for the sorption of $\mathrm{Ni}, \mathrm{Cu}$ and $\mathrm{Pb}$ in the filtrate and reference solution

\begin{tabular}{|c|c|c|c|c|c|c|}
\hline & & \multicolumn{2}{|c|}{ Reference } & \multicolumn{2}{|c|}{ Filtrate } & \multirow[t]{2}{*}{$K_{1} / K_{2}$} \\
\hline & & $K_{1}$ & $R^{2}$ & $K_{2}$ & $R^{2}$ & \\
\hline \multirow{8}{*}{$\mathrm{Ni}$} & $\mathrm{S}_{1}$ & 29.11 & 0.996 & 3.65 & 0.868 & 8.0 \\
\hline & $\mathrm{S}_{2}$ & 20.63 & 0.992 & 5.39 & 0.989 & 3.5 \\
\hline & $\mathrm{S}_{3}$ & 29.87 & 0.991 & 6.21 & 0.999 & 4.8 \\
\hline & $\mathrm{S}_{4}$ & 22.45 & 0.950 & 7.05 & 0.992 & 3.2 \\
\hline & $\mathrm{S}_{5}$ & 24.32 & 0.971 & 9.68 & 0.940 & 2.5 \\
\hline & $\mathrm{S}_{6}$ & 28.20 & 0.995 & 5.37 & 0.923 & 5.3 \\
\hline & $\mathrm{S}_{7}$ & 131.79 & 0.906 & 26.04 & 0.915 & 5.1 \\
\hline & $\mathrm{S}_{8}$ & 91.42 & 0.991 & 25.00 & 0.959 & 3.7 \\
\hline \multirow{8}{*}{$\mathrm{Cu}$} & $\mathrm{S}_{1}$ & 29.11 & 0.985 & 4.80 & 0.979 & 6.1 \\
\hline & $\mathrm{S}_{2}$ & 22.44 & 0.969 & 2.74 & 0.984 & 8.2 \\
\hline & $\mathrm{S}_{3}$ & 22.04 & 0.995 & 7.54 & 0.940 & 2.9 \\
\hline & $\mathrm{S}_{4}$ & 54.38 & 0.984 & 18.56 & 0.993 & 2.9 \\
\hline & $\mathrm{S}_{5}$ & 13.98 & 0.961 & 5.56 & 0.984 & 2.5 \\
\hline & $\mathrm{S}_{6}$ & 10.18 & 0.986 & 0.98 & 0.956 & 10.3 \\
\hline & $\mathrm{S}_{7}$ & 37.11 & 0.927 & 3.98 & 0.924 & 9.3 \\
\hline & $\mathrm{S}_{8}$ & 34.88 & 0.939 & 4.39 & 0.968 & 7.9 \\
\hline \multirow{8}{*}{$\mathrm{Pb}$} & $\mathrm{S}_{1}$ & 81.95 & 0.990 & 13.17 & 0.979 & 6.2 \\
\hline & $\mathrm{S}_{2}$ & 22.71 & 0.954 & 4.91 & 0.974 & 4.6 \\
\hline & $\mathrm{S}_{3}$ & 23.33 & 0.989 & 2.10 & 0.967 & 11.1 \\
\hline & $\mathrm{S}_{4}$ & 130.49 & 0.971 & 17.56 & 0.965 & 7.4 \\
\hline & $\mathrm{S}_{5}$ & 7.90 & 0.982 & 2.30 & 0.980 & 3.4 \\
\hline & $\mathrm{S}_{6}$ & 27.38 & 0.980 & 1.33 & 0.992 & 20.6 \\
\hline & $\mathrm{S}_{7}$ & 68.12 & 0.966 & 2.66 & 0.981 & 25.6 \\
\hline & $\mathrm{S}_{8}$ & 10.03 & 0.988 & 1.27 & 0.968 & 7.9 \\
\hline
\end{tabular}

The probability level of $p<0.05$. the following descending order: $\mathrm{Pb}^{2+}>\mathrm{Cu}^{2+}>\mathrm{Ni}^{2+}$. Among the soils, the ratios were higher for soils $\mathrm{S}_{6}$ (Wuhan) and $\mathrm{S}_{7}$ (Gansu) than the corresponding values for the other soils.

\subsection{Influence of soil properties on sorption of $\mathrm{Ni}, \mathrm{Cu}$ and $\mathrm{Pb}$}

Sorptions of $\mathrm{Ni}, \mathrm{Cu}$ and $\mathrm{Pb}$ were different among the soils. Therefore, relationship between the sorption parameters and soil properties was described by stepwise multiple linear regression. The variables were $\mathrm{pH}, \mathrm{CEC}, \mathrm{OM}, \mathrm{DOC}$, clay content and the dependent variable was the sorption constant $K$, which represents the sorption affinity.

The regression equations obtained are listed in Table 4 . The sorption constant $K$ was correlated with CEC for $\mathrm{Ni}$ and with $\mathrm{OM}$ for $\mathrm{Pb}$ and $\mathrm{Cu}$. Such differences could contribute to the different complexing ability between the metals of $\mathrm{Ni}$ and $\mathrm{Pb}$ or $\mathrm{Cu}$ to soil clays and soil organic matters. In most cases same dependent variables were adapted into the regression equations for the heavy metals in the filtrate and reference solutions, indicating sorption of these metals in filtrates and reference solutions was dependent on the same soil physicochemical properties.

\subsection{Sludge application rates}

In order to investigate the effect of decreased $\mathrm{Ni}, \mathrm{Cu}$ and $\mathrm{Pb}$ sorption on the sludge application due to the interactions

Table 4

Relationship between the metal sorption and the soil properties

\begin{tabular}{lll}
\hline Metal & Equation & $R^{2}$ \\
\hline $\mathrm{Ni}$ (filtrate) & $M=0.640[\mathrm{CEC}]-2.186$ & 0.803 \\
$\mathrm{Ni}$ (reference) & $M=2.926[\mathrm{CEC}]-13.314$ & 0.815 \\
$\mathrm{Cu}$ (filtrate) & $M=5.088[\mathrm{OM}]-4.386$ & 0.866 \\
$\mathrm{Cu}$ (reference) & $M=12.979[\mathrm{OM}]+0.555[\mathrm{CEC}]-10.130$ & 0.813 \\
$\mathrm{~Pb}$ (filtrate) & $M=5.628[\mathrm{OM}]-5.902$ & 0.802 \\
$\mathrm{~Pb}$ (reference) & $M=38.985[\mathrm{OM}]-34.986$ & 0.759
\end{tabular}

The probability level of $p<0.05$. 

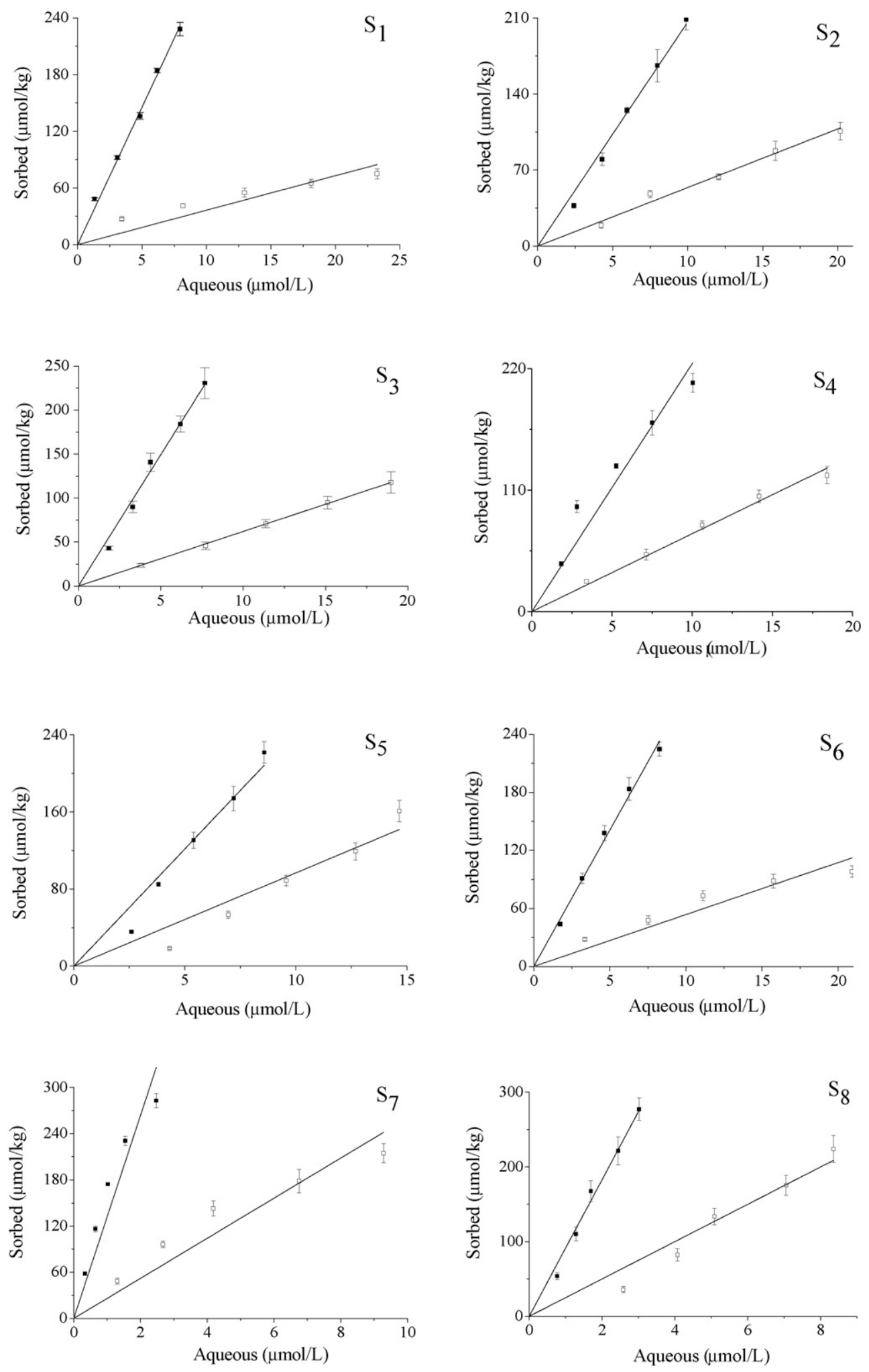

Fig. 1. Sorption isotherms of Ni by soils determined by equilibration with sludge filtrate ( $\square$ ) and the reference solution (

between DOC and the heavy metals, application rates calculated on the basis of the filtrate sorption parameters were compared with those of the reference solution (Table 5). The rates without considering dissolved organo-metallic complexes were much higher than those with the influence of such complexes consid- ered. If dissolved organo-metallic complexes were considered in the calculation, the rates of approximate $6.0,3.4,1.9,10.0$, 6.3, 3.6, 7.3 and 3.5 t-sludge/ha were recommended for $\mathrm{S}_{1}$ (Beijing), $S_{2}$ (Jiangxi), $S_{3}$ (Xiamen), $S_{4}$ (Jilin), $S_{5}$ (Guangdong), $\mathrm{S}_{6}$ (Wuhan), $\mathrm{S}_{7}$ (Gansu) and $\mathrm{S}_{8}$ (Xinjiang), respectively. How- 

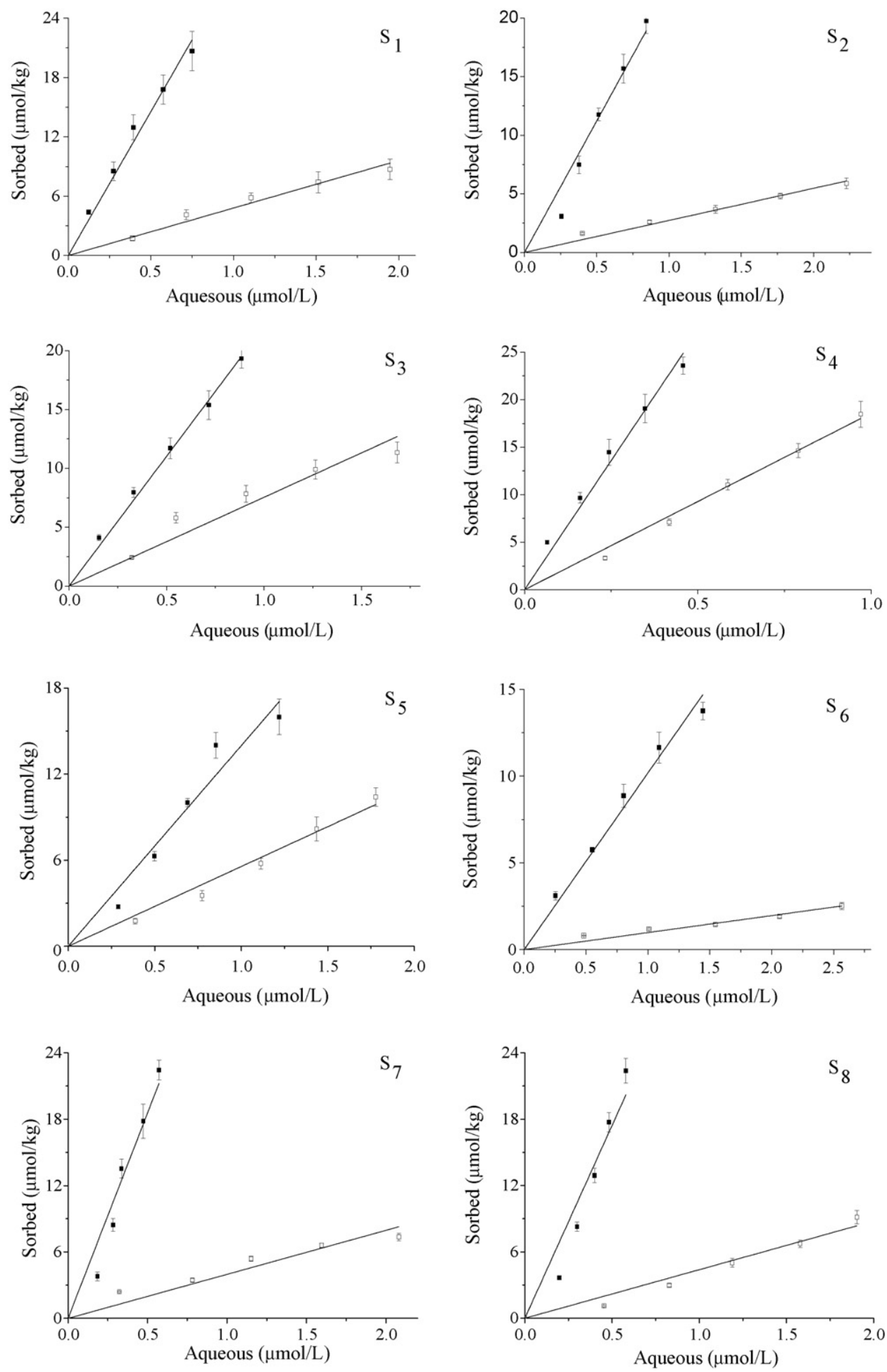

Fig. 2. Sorption isotherms of $\mathrm{Cu}$ by soils determined by equilibration with sludge filtrate ( $\square$ ) and the reference solution ( $\square$ ).

ever, if the influence of such complexes were not considered (by using the sorption parameters derived from the reference solution), much greater application rates of approximate $47.8,51.4$, 34.2, 31.3, 21.7, 46.3, 187.1 and 27.6 t-sludge/ha were obtained for $S_{1}$ (Beijing), $S_{2}$ (Jiangxi), $S_{3}$ (Xiamen), $S_{4}$ (Jilin), $S_{5}$ (Guangdong), $\mathrm{S}_{6}$ (Wuhan), $\mathrm{S}_{7}$ (Gansu) and $\mathrm{S}_{8}$ (Xinjiang) soils, respectively.

\section{Discussion}

The sewage sludge filtrate has a relatively high content of dissolved organic carbon $(1245.6 \mathrm{mg} / \mathrm{L})$, of which $53 \%$ was within the hydrophilic DOC fraction. The large proportion of hydrophilic DOC could contribute to the composting processes. It was reported that hydrophilic DOC fraction mainly consists 

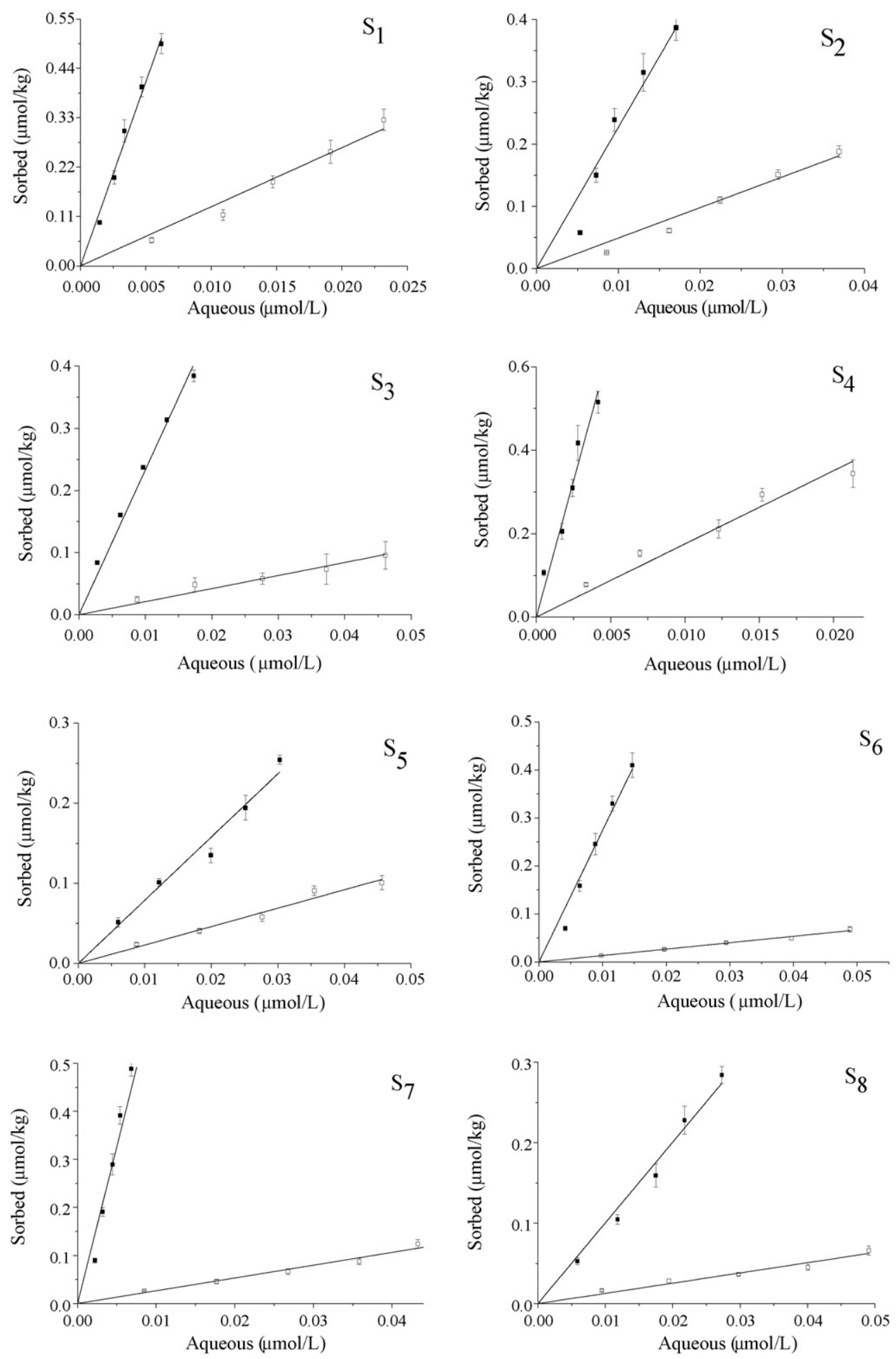

Fig. 3. Sorption isotherms of Pb by soils determined by equilibration with sludge filtrate $(\square)$ and the reference solution (

of simple organic acids, polypydroxy phenols, carbohyfrates, amino acids and amino sugars [26] and these compounds favored the formation of dissolved organo-metallic complexes. The MINTEQAII speciation results showed that the majority of filtrate $\mathrm{Ni}, \mathrm{Cu}$ and $\mathrm{Pb}$ was present as dissolved organo-metallic complexes. The formation of organic complexes, therefore, should be the major contribution to the significant decrease in the sorption of $\mathrm{Ni}, \mathrm{Cu}$ and $\mathrm{Pb}$ as evidenced by the sorption isotherms (Figs. 1-3) and sorption constants obtained (Table 3).

Equations in Table 4 verified that sorption of metals was described by the soil SOM for $\mathrm{Cu}$ and $\mathrm{Pb}$ and CEC for $\mathrm{Ni}$. Soil organic matter can not only provide sorption sites for metals directly, but also combine with soil minerals and increase the sorption sites [27]. Stevenson [28] has reported that since 
Table 5

Estimated environmentally safe sorbed $\mathrm{Ni}, \mathrm{Cu}$ and $\mathrm{Pb}$ concentrations, metal loadings, and sludge application rates

\begin{tabular}{|c|c|c|c|c|c|c|}
\hline & \multicolumn{2}{|l|}{$\mathrm{Ni}$} & \multicolumn{2}{|l|}{$\mathrm{Cu}$} & \multicolumn{2}{|l|}{$\mathrm{Pb}$} \\
\hline & Reference & Filtrate & Reference & Filtrate & Reference & Filtrate \\
\hline \multicolumn{7}{|c|}{ Sorbed metal concentration $(\mu \mathrm{g} / \mathrm{kg})$} \\
\hline $\mathrm{S}_{1}$ & 582.2 & 73.0 & 58,220 & 30,620 & 819.5 & 355.8 \\
\hline $\mathrm{S}_{2}$ & 626.2 & 41.8 & 44,880 & 5,480 & 227.1 & 49.1 \\
\hline $\mathrm{S}_{3}$ & 597.4 & 23.8 & 44,080 & 15,080 & 233.30 & 21.0 \\
\hline $\mathrm{S}_{4}$ & 381.6 & 121.6 & 108,760 & 37,120 & 1304.9 & 175.6 \\
\hline $\mathrm{S}_{5}$ & 1071.0 & 131.8 & 27,960 & 1,460 & 79.0 & 23.0 \\
\hline $\mathrm{S}_{6}$ & 564.0 & 107.4 & 20,240 & 1,760 & 273.8 & 13.3 \\
\hline $\mathrm{S}_{7}$ & 2635.8 & 520.8 & 74,220 & 7,960 & 681.2 & 26.6 \\
\hline $\mathrm{S}_{8}$ & 1828.6 & 500.0 & 69,760 & 8,780 & 100.3 & 12.7 \\
\hline \multicolumn{7}{|c|}{ Metal loading (kg/ha) } \\
\hline $\mathrm{S}_{1}$ & 1.31 & 0.16 & 131.00 & 68.90 & 1.84 & 0.80 \\
\hline $\mathrm{S}_{2}$ & 1.41 & 0.09 & 100.98 & 12.33 & 0.51 & 0.11 \\
\hline $\mathrm{S}_{3}$ & 1.34 & 0.05 & 99.18 & 33.93 & 0.52 & 0.05 \\
\hline $\mathrm{S}_{4}$ & 0.86 & 0.27 & 244.71 & 83.52 & 2.94 & 0.40 \\
\hline $\mathrm{S}_{5}$ & 2.41 & 0.30 & 62.91 & 3.29 & 0.18 & 0.05 \\
\hline $\mathrm{S}_{6}$ & 1.27 & 0.24 & 45.54 & 3.96 & 0.62 & 0.03 \\
\hline $\mathrm{S}_{7}$ & 5.93 & 1.17 & 167.00 & 17.91 & 1.53 & 0.06 \\
\hline $\mathrm{S}_{8}$ & 4.11 & 1.13 & 156.96 & 19.76 & 0.23 & 0.03 \\
\hline \multicolumn{7}{|c|}{ Sludge application rate (t/ha) } \\
\hline $\mathrm{S}_{1}$ & 47.8 & 6.0 & 686.3 & 361.0 & 225.1 & 97.8 \\
\hline $\mathrm{S}_{2}$ & 51.4 & 3.4 & 529.1 & 64.6 & 62.4 & 13.5 \\
\hline $\mathrm{S}_{3}$ & 49.1 & 1.9 & 519.6 & 177.8 & 64.1 & 5.8 \\
\hline $\mathrm{S}_{4}$ & 31.3 & 10.0 & 1282.1 & 437.6 & 358.5 & 48.2 \\
\hline $\mathrm{S}_{5}$ & 87.9 & 10.8 & 329.6 & 17.2 & 21.7 & 6.3 \\
\hline $\mathrm{S}_{6}$ & 46.3 & 8.8 & 238.6 & 20.8 & 75.2 & 3.6 \\
\hline $\mathrm{S}_{7}$ & 216.4 & 42.8 & 874.9 & 93.8 & 187.1 & 7.3 \\
\hline $\mathrm{S}_{8}$ & 150.2 & 41.1 & 822.4 & 103.5 & 27.6 & 3.5 \\
\hline
\end{tabular}

SOM was tightly bound to clay minerals and its reactive sites were likely to be occupied by divalent ions. On the other hand, SOM has a large number of negative charges on their surface, thus it attracts cation elements and also contributes to a higher CEC. The CEC is an index of the capacity to exchange cations with the soil solution. It affects the ability of soil to adsorb and retain cations and heavy metals. Previous study [29] showed soil texture affected heavy metal mobility because clay has negatively charged functional groups to which the positively charged divalent heavy metals could be bound. However, in this study, the clay contents did not appear as a variable in the regression equations between metal adsorption and the soil properties. One possibility could be the soil properties being changed concomitantly [30] and, therefore, the contribution of clay contents was reflected by other properties, such as the CEC. The contents of DOC in soils were very low comparing with the DOC in sewage sludge filtrate; therefore, its effect was insignificant.

China guideline (GB42-84) sets limits for the $\mathrm{Ni}, \mathrm{Cu}$ and $\mathrm{Pb}$ contents of land-applied sewage sludge, as well as the annual maximum land application quantities. These application quantities are primarily based on phyto-toxicological aspects. It is widely accepted that sorption is an important process controlling mobility and thereby transportation of heavy metals in soil [31,32]. More appropriate sludge application estimates may be obtained from site-specific sorption information [33]. It might be possible, at least for comparison purposes, to estimate sewage sludge land application rate by using sorption isotherm parameters. Sludge application rates calculated without considering the effects of the sludge-derived DOM were much higher than the values with such consideration, which gives us a hint that the influence of sludge derived DOM should be considered as an important factor in sludge application calculation. The real sludge application risk was certainly determined by many other factors except for the sludge matrix and soil properties, such as land usage, microbial activity and plant root-soil interactions [34-37]. The complicated influences make it difficult to set a real limit for sludge application and scientists continue making efforts with different consideration.

\section{Acknowledgements}

This work was funded by Beijing Key Technologies R\&D Program (Grant No. D0706007040291) and Chinese Academy of Sciences (Grant No. KZCX3-SW-431).

\section{References}

[1] G.C. Sigua, M. Adjei, J. Rechcigl, Cumulative and residual effects of repeated sewage sludge applications: forage productivity and soil quality implications in south Florida, USA, Environ. Sci. Pollut. Res. 12 (2) (2005) 80-88.

[2] S. Selivanovskaya, V. Latypova, The Use of bioassays for evaluating the toxicity of sewage sludge and sewage sludge-amended soil, J. Soil. Sediment. 3 (2) (2003) 85-92.

[3] K.P. Singh, D. Mohan, S. Sinha, R. Dalwani, Impact assessment of treated/untreated wastewater toxicants discharged by sewage treatment plants on health, agricultural, and environmental quality in the wastewater disposal area, Chemosphere 55 (2004) 227-255.

[4] G.R. Parker, W.W. McFee, J.M. Kelly, Metal distribution in forested ecosystems in urban and rural north-western Indiana, J. Environ. Qual. 7 (1978) 337-342.

[5] A.C. Chang, J.W. Warneke, A.L. Page, L.J. Lund, Accumulation of heavy metals in sewage sludge treated soils, J. Environ. Qual. 13 (1984) 87-91.

[6] T. Schiradoe, I. Vergara, E.B. Schalska, P.F. Pratt, Evidence for movement of heavy metals in a soil irrigated with untreated waste-water, J. Environ. Qual. 15 (1986) 9-12.

[7] R.H. Dowdy, J.J. Latterell, T.D. Hinesly, R.B. Grossman, D.L. Sullivan, Trace metal movement in an aeric ochraqualf following 14 years of annual sludge applications, J. Environ. Qual. 20 (1991) 119-123.

[8] P.F. Bell, B.R. James, R.L. Chaney, Heavy metal extractability in long-term sewage sludge and metal salt-amended soils, J. Environ. Qual. 20 (1991) 481-486.

[9] M.B. McBride, B.K. Richards, T. Steenhuis, J.J. Russo, S. Sauve, Mobility and solubility of toxic metals and nutrients in soil fifteen years after sludge application, Soil Sci. 162 (1997) 487-500.

[10] D.J. Ashworth, B.J. Alloway, Soil mobility of sewage sludge-derived organic matter, copper, nickel and zinc, Environ. Pollut. 127 (2004) $137-144$.

[11] E.D. Burton, D.W. Hawker, M.R. Redding, Estimating sludge loadings to land based on trace metal sorption in soil: effect of dissolved organometallic complexes, Water Res. 37 (2003) 1394-1400.

[12] F.M. Dunnivant, P.M. Jardine, D.L. Taylor, J.F. McCarthy, Transport of naturally occurring dissolved organic carbon in laboratory columns containing aquifer material, Soil Sci. Soc. Am. J. 56 (1992) 437-444.

[13] R. Naidu, N.S. Bolan, R.S. Kookana, K.G. Tiller, Ionic-strength and pH effects on the sorption of cadmium and the surface charge of soils, Eur. J. Soil Sci. 45 (1994) 419-429.

[14] R.G. Gerriste, W. Van Driel, The relationship between adsorption of trace metals, organic matter and $\mathrm{pH}$ in temperate soils, J. Environ. Qual. 13 (1984) 197-204. 
[15] B.E. Udom, J.S.C. Mbagwu, J.K. Adesodun, N.N. Agbim, Distributions of zinc, copper, cadmium and lead in a tropical ultisol after long-term disposal of sewage sludge, Environ. Inter. 30 (2004) 467-470.

[16] B. Buchter, B. Davidoff, M.C. Amacher, C. Hinz, I.K. Iskandar, H.M. Selim, Correlation of Freundlich $K_{\mathrm{d}}$, and $\mathrm{n}$ retention parameters with soils and elements, Soil Sci. 148 (1989) 370-381.

[17] G.C. Sigua, Current and future outlook of dredged and sewage sludge materials in agriculture and environment, J. Soil Sediment. 5 (1) (2005) $50-52$.

[18] J.A. Leenheer, Comprehensive approach to preparative isolation and fractionation of dissolved organic carbon from natural waters and wastewaters, Environ. Sci. Technol. 15 (1981) 578-587.

[19] J.D. Rhoades, Soluble salts, in: A.L. Page, R.H. Miller, D.R. Keegy (Eds.), Methods of Soil Analysis, Part 2, second ed., American Society of Agronomy Inc. and Soil Science Society of American Inc. Publisher, Madison, 1982, pp. 181-199.

[20] S.D. Nelson, L.E. Sommers, Total carbon, organic carbon, and organic matter. In: A.L. Page, et al. (Ed.), Methods of Soil Analysis, Part 2, second ed., Agron. Monogr. 9. ASA and SSSA, Madison, WI, 1982, pp. 539579.

[21] P.R. Day, Particle fractionation and particle-size analysis, in: C.A. Black (Ed.), Methods of Soil Analysis, Part 1, American Society of Agronomy, Inc., Madison, Wisconsin, 1965, pp. 545-567.

[22] WHO, Guidelines for Drinking-water Quality, second ed., vol. 1, Recommendations Geneva, 1993.

[23] J.D. Allison, D.S. Brown, K.J., Novo-Gradac, MINTEQA2 PRODEFA2, A Geochemical Assessment Model for Environmental Systems, Version 3.0 Users Manual. US Environmental Protection Agency, Athens, G.A. (EPA/600/3-91/021), 1991.

[24] T.B. Cheng, Q.F. Huang, D. Gao, Y.Q. Zheng, J.F. Wu, Heavy metal concentrations and their decreasing trends in sludges of china, Acta Sci. Circumst. 23 (5) (2003) 561-569, in Chinese.

[25] B.K. Mandal, K.T. Suzuki, Arsenic round the world: a review, Talanta 58 (2002) 201-235.
[26] T.R. Fox, N.B. Comerfield, Low molecular weight organic acid in selected forest soils of the south-eastern USA, Soil Sci. Soc. Am. J. 54 (1990) 1763-1767.

[27] K. Kaiser, G. Guggenberger, Mineral surfaces and soil organic matter, Eur. J. Soil Sci. 54 (2003) 219-236.

[28] F.J. Stevenson, Stability constants of $\mathrm{Cu}^{2+}, \mathrm{Pb}^{2+}$, and $\mathrm{Cd}^{2+}$ complexes with humic acids, Soil Sci. Soc. Am. J. 40 (1976) 665-672.

[29] B.K. Richards, T.S. Steenhuis, J.H. Peverly, M.B. McBride, Effect of sludge-processing mode, soil texture and soil $\mathrm{pH}$ on metal mobility in undisturbed soil columns under accelerated loading, Environ. Pollut. 109 (2000) 327-346.

[30] M.E. Alves, A. Lavorenti, Sulfate adsorption and its relationships with properties of representative soils of the Săo Paulo State, Brazil, Geoderma 118 (2004) 89-99.

[31] B.J. Alloway, Heavy Metals in Soils, second ed., Blackie Academic and Professional, Melbourne, 1995.

[32] M.B. McBride, Reactions controlling heavy metal solubility in soils, Adv. Soil Sci. 10 (1989) 1-56.

[33] G.A. Barry, P.J. Chudek, E.K. Best, P.W. Mody, Estimating sludge application rates to land based on heavy metal and phosphorus sorption characteristics of soil, Water Res. 29 (1995) 2031-2034.

[34] S. Qureshi, B. Richards, A. Hay, C. Tsai, M. McBride, P. Baveye, T. Steenhuis, Effect of microbial activity on trace element release from sewage sludge, Environ. Sci. Technol. 37 (15) (2003) 3361-3366.

[35] S. Qureshi, B.K. Richards, T.S. Steenhuis, M.B. McBride, P. Baveye, S. Dousset, Microbial acidification and $\mathrm{pH}$ effects on trace element release from sewage sludge, Environ. Pollut. 132 (1) (2004) 61-71.

[36] V. Séguin, F. Courchesne, C. Gagnon, R.R. Martin, G.R. Gobran, Solid phase metal fractionation as affected by organic matter in the rhizosphere of forested soils, in: Transactions of the 17th World Congress of Soil Science, Bangkok, Thailand, 2002, pp. 888.1-888.9.

[37] P. Vervaeke, F.M.G. Tack, N. Lust, M. Verloo, Short- and longer-term effects of the willow root system on metal extractability in contaminated dredged sediment, J. Environ. Qual. 33 (2004) 976-983. 